\title{
Interdisciplinary Integration of the CVS Module and Its Effect on Faculty and Student Satisfaction as Well as Student Performance
}

\author{
Nasra N Ayuob ${ }^{1,2^{*}}$, Basem S Eldeek ${ }^{1,2}$, Lana A Alshawa ${ }^{1}$ and Abdulrahman F ALsaba ${ }^{3,4}$
}

\begin{abstract}
Background: Beyond the adoption of the principles of horizontal and vertical integration, significant planning and implementation of curriculum reform is needed. This study aimed to assess the effect of the interdisciplinary integrated Cardiovascular System (CVS) module on both student satisfaction and performance and comparing them to those of the temporally coordinated CVS module that was implemented in the previous year at the faculty of Medicine of the King Abdulaziz University, Saudi Arabia.

Methods: This interventional study used mixed method research design to assess student and faculty satisfaction with the level of integration within the CVS module. A team from the medical education department was assembled in 2010/2011 to design a plan to improve the CVS module integration level. After delivering the developed module, both student and faculty satisfaction as well as students performance were assessed and compared to those of the previous year to provide an idea about module effectiveness.

Results: Many challenges faced the medical education team during design and implementation of the developed CVS module e.g. resistance of faculty members to change, increasing the percentage of students directed learning hours from the total contact hour allotted to the module and shifting to integrated item writing in students assessment, spite of that the module achieved a significant increase in both teaching faculty and student satisfaction as well as in the module scores.

Conclusion: The fully integrated CVS has yielded encouraging results that individual teachers or other medical schools who attempt to reformulate their curriculum may find valuable.
\end{abstract}

Keywords: Implementation, Interdisciplinary, Curriculum, Integration, Pre-clerkship, Cardio-vascular module

\section{Background}

The prevailing trend in basic science curriculum changes around the world is now towards integration, both horizontally among the disciplines and vertically between basic and clinical sciences [1-4]. Many researchers have proven that information presented without robust crosslinks and ties to clinical applications, which is tested in isolation from related subject matter, has proven difficult for students to recall after the transition to clinical clerkships [5-7].

\footnotetext{
* Correspondence: nasra_ayuob@yahoo.com

${ }^{1}$ Medical Education Department, Faculty of Medicine, King Abdulaziz University, Jeddah, Saudi Arabia

${ }^{2}$ Faculty of Medicine, Mansoura University, Mansoura, Egypt

Full list of author information is available at the end of the article
}

Harvard Medical School created a hybrid curriculum in 1985 that combined problem based learning (PBL) with limited lectures and laboratories in order to help students to develop a flexible, integrated knowledge base. It demonstrated that students could learn basic science in the context of clinical medicine and humanistic care while maintaining sufficient content mastery to pass the national licensing examination with no decrement in basic science knowledge [8].

Recognizing the limitations of its own traditional, discipline-based curriculum, the faculty of medicine at King Abdulaziz University (KAU) challenged both the clinical and basic science faculty members to create a new integrated curriculum to be implemented in the academic year of $2006 / 2007$. The curriculum at KAU

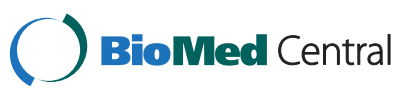


consists of two phases. In phase I (the pre-clinical phase) the basic sciences are taught in the form of a few core courses and system-based modules such as cardiovascular module. Phase II clinical years include the major four clerkships, in addition to some sub-specialties and a professionalism course.

Despite committee initiatives to establish integration between module content (to be temporally coordinated), student satisfaction assessed at the end of the last two academic years (2008/2009 and 2009/2010) showed incomplete satisfaction with the integration within the modules. In response to these complaints, the medical education department (MED) took a pioneering step, in association with the cardiovascular system module committee, to present an interdisciplinary integration model in the academic year of $2010 / 2011$. This paper aimed to document the steps taken to establish such integration as well as to assess its effect on student satisfaction and performance. It will serve as a useful example for other schools aiming to improve integration levels in their curriculum.

\section{Methods}

This interventional study used mixed method research and collected both qualitative and quantitative data to assess the effectiveness of the integrated CVS module. An ethical approval of this research article has been obtained from the biomedical research ethics committee at the Faculty of Medicine, King Abdulaziz University.

\section{Steps taken by the ME team:}

- A focus group discussion with those faculty members participating in system based modules teaching was facilitated by MED. Ten faculty members from the basic science departments and three from the clinical departments had participated in the discussion about; their satisfaction with the integration level in the module and comments and/or complaints that had been raised by students during and at the end of all modules.

- Reviewing the CVS module evaluations (quantitative method) filled out by the second year medical students and faculty members in the last two academic years (2008/2009 and 2009/2010) as a pilot to triangulate the results of the focus group discussion. This review revealed incomplete satisfaction of both faculty members and students with the integration within the CVS module.

- Conducting a detailed review of the literature, looking for similar problems in the implementation of integration and the experiences and approaches taken to solve it.
- Putting a developmental plan for enhancing integration. The CVS module was select as a model to work on because the module chairman and teaching faculty members were very enthusiastic about increasing the integration level within their module. This module is taught to the second year medical students. It has four credit hours (about 60 contact hours) distributed among lectures, practical sessions, PBL sessions, tutorials and SDL as seen in Table 1. Six disciplines; anatomy, physiology, biochemistry, pharmacology, pathology and cardiology were temporally coordinated in this module.

- Revision of the module objectives and the objectives of each session. They correlated these objectives to the faculty program objectives. The redundant objectives were deleted while missed ones were added.

- A theme, in the form of a clinical problem, was set for each week of the four weeks of the module. These themes were chosen with the help of the relevant clinician and according to the commonality across the module objectives and the Saudi Arabian community. The chosen themes were: heart failure, atherosclerosis and ischemic heart diseases, hypertension and arrhythmias.

- Next came regrouping the module objectives around the chosen themes and reorganizing the teaching and learning activities (lectures, practical, tutorial, SDL and PBL sessions) to follow the themes.

- Developing PBL cases to cover different themes.

- Designing a comprehensive timetable for each week Figure 1.

- Advising teaching faculty members turned to case-based teaching of the basic sciences in order to enhance the vertical integration within the module and increased the students' perception of the clinical relevance of basic sciences.

Table 1 Time (in hours) allotted to different teaching and learning methods before modification the CVS module

\begin{tabular}{lllllll}
\hline & \multicolumn{2}{c}{ Lecture Practice Tutorial PBL } & $\begin{array}{c}\text { Clinical } \\
\text { presentation }\end{array}$ & SDL Total \\
\hline Anatomy & 5 & 3 & 1 & & 2 & \\
Physiology & 13 & 2 & & & & \\
Biochemistry & 4 & 2 & & & & \\
Pathology & 7 & 2 & 1 & & & 2 \\
Pharmacology & 4 & 1 & & & 2 & 2 \\
Medicine & 2 & & & & 2 & \\
Total & 35 & 10 & 2 & 8 & 2 &
\end{tabular}

PBL: problem based learning.

SDL: student directed learning. 


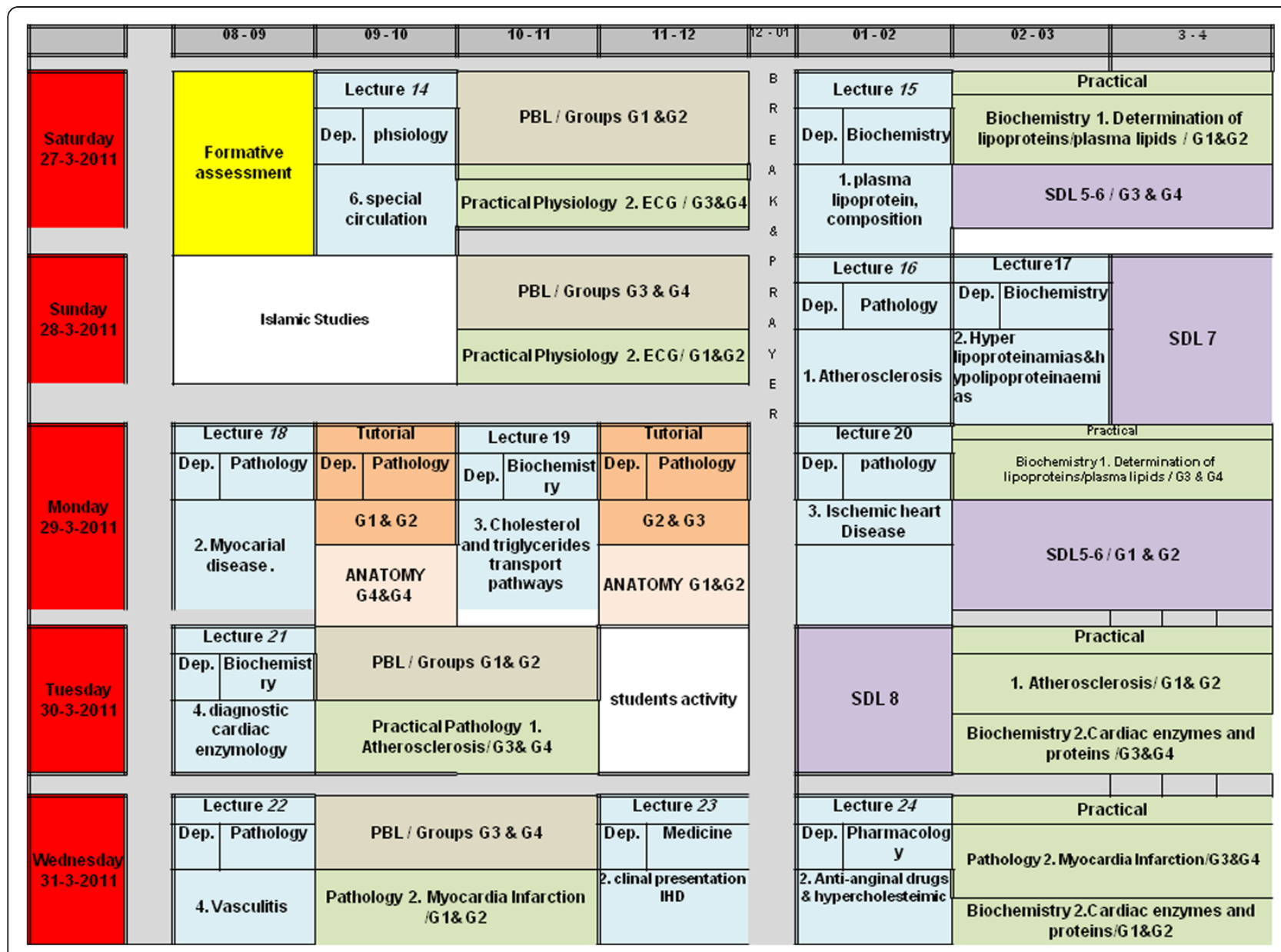

Figure 1 Example of a comprehensive time-table for a week of the CVS module under the theme "Atheroscelorosis and ischemic heart diseases.

- Increasing the SDL weight to occupy about $18 \%$ of the time allotted to the module, Table 2 and developing procedures to standardize it.

- Regarding the assessment, a workshop to train faculty members on constructing integrated items was held by the ME team. The assessment tools presented in the workshop included problem-based questions ( $\mathrm{PBQ}$ ), modified essay questions (MEQs) and objective structured practical examination (OSPE). These tools were used intentionally to assess the higher levels of cognition such as application and evaluation of knowledge.

This was accomplished after the development of an exam blueprint through the collaboration between the ME team and the CVS module members.

Table 2 Time (in hours) allotted to different teaching and learning methods after modification of the CVS module

\begin{tabular}{|c|c|c|c|c|c|c|c|c|c|c|}
\hline Theme & week & Physiology & Anatomy & Pathology & Biochemistry & Pharmacology & Medicine & PBL & SDL & Total \\
\hline Heart failure & $1^{\text {st }}$ & L: 5 P: 1 & L: 2 P: 2 & & & $\mathrm{~L}: 1$ & L: 1 CP:1 & & 4 & L:9 P:3 CP:1 \\
\hline $\begin{array}{l}\text { Arthrosclerosis/ } \\
\text { Ischemic Heart Disease }\end{array}$ & $2^{\text {nd }}$ & & $\mathrm{L}: 1$ & $\mathrm{~L}: 4 \mathrm{T:} 1$ & L: 4 P: 2 & $\mathrm{~L}: 1$ & $\mathrm{~L}: 1$ & 4 & 4 & L: 11 P: 2 T: 1 \\
\hline Hypertension & $3^{\text {rd }}$ & L: 5 P: 1 & $\mathrm{~L}: 1 \mathrm{~T}: 1$ & $\mathrm{~L}: 1$ & & $\mathrm{~L}: 1$ & $\mathrm{~L}: 1$ & 4 & - & $\mathrm{L}: 9 \mathrm{P}: 1 \mathrm{~T}: 1$ \\
\hline $\begin{array}{l}\text { Arrhythmia/ } \\
\text { Rheumatic Heart Disease }\end{array}$ & $4^{\text {th }}$ & $\mathrm{L}: 2$ & & L: $2 P: 2$ & & L: 1 P: 1 & L: 1 CP:1 & & 3 & L: 6 P: 3 CP:1 \\
\hline Total & 4 & L: 12 P: 2 & L: 4 P: 3 T:1 & L: 7 P: 2 T: 1 & L: 4 P: 2 & L: 4 P: 1 & $\mathrm{~L}: 4$ & 8 & 11 & L: 35 P:10 T:2 CP:2 \\
\hline
\end{tabular}

L: Lecture.

P: Practical.

T: Tutorial.

CP: Clinical Presentation. 
- Highlighting the importance of formative assessment through demonstrating its role in providing students with feedback on their performance, helping them detecting their gaps of knowledge, planning to fill these gaps and familiarizing them with the newly used assessment tools before the final summative exam.

- Maintaining a close monitoring and follow up process to ensure proper implementation of what has been planned. This was accomplished formally through direct contact with the head of the CVS module.

- To measure the effectiveness of the developed module, both faculty and student satisfaction was measured via module evaluation questionnaires. The results were compared with results measured in the academic year of 2009/2010. Student assessment results, in the form of overall success rate and the percentage of students grades as well as the item analysis results of the CVS exams for the two consecutive years (2009/2010) and (2010/2011), were also compared.
- Statistical analysis was undertaken using a statistical package of social science (SPSS) software, version 16 (2005). The qualitative data were presented in the form of number and percentage. A chi-square test, with linear trends, was used for ordinal qualitative data. A percentage rate for teaching faculty member satisfaction was calculated for the module evaluation. Significance was considered at $\mathrm{p}$ value less than 0.05 .

\section{Results}

Focus group discussion with the faculty members participating in system based modules in the years from 2008-2010 revealed incomplete satisfaction which the integration level in their particular modules.

In spite of the initial resistance among some faculty members towards the developed integrated CVS module during its preparatory phase, the result of focus group discussion, after implementation of the developed module, revealed an increase in satisfaction with the module. They even sought help from ME team members to

Table 3 Results of students responses to course evaluation questionnaire (in relation to module contents and faculty members) of the CVS module in (2009/2010) and (2010/2011)

\begin{tabular}{|c|c|c|c|}
\hline Items of comparison & $\begin{array}{c}2009 / 2010 \\
\text { Satisfaction } \\
N=129 \\
\%\end{array}$ & $\begin{array}{c}2010 / 2011 \\
\text { Satisfaction } \\
N=152 \\
\%\end{array}$ & $\begin{array}{c}\text { Test of } \\
\text { significance }\end{array}$ \\
\hline \multicolumn{4}{|c|}{ Module contents } \\
\hline Objectives of course are clear & 69.5 & 93 & $P<0.001^{* * *}$ \\
\hline Objectives of each teaching formats were explained at its start & 69 & 85 & $P=0.002^{* *}$ \\
\hline $\begin{array}{l}\text { The modules contents show relation between basic \& clinical } \\
\text { sciences }\end{array}$ & 81.1 & 89 & $P=0.089$ \\
\hline The practical part is related to the theoretical part & 67.4 & 87 & $\mathrm{P}<0.001^{* * *}$ \\
\hline This course help to develop my self-learning capacity & 63.3 & 86 & $\mathrm{P}<0.001^{* * *}$ \\
\hline PBL sessions improve my learning achievements & 61.7 & 80 & $P=0.001^{* *}$ \\
\hline This course is good \& useful for my future career & 80.9 & 94 & $\mathrm{P}<0.001^{* * * *}$ \\
\hline Overall satisfaction & 70.5 & 87.5 & $P<0.01^{* *}$ \\
\hline \multicolumn{4}{|c|}{ Faculty members } \\
\hline address the contents of the module as stated study guide & 64 & 82 & $P=0.002^{* *}$ \\
\hline encourage students to ask questions during teaching & 37.7 & 74 & $\mathrm{P}<0.001^{* * *}$ \\
\hline make good use of different types of educational methods & 46.1 & 73 & $\mathrm{P}<0.001^{* * *}$ \\
\hline Faculty members use clinical cases in teaching & 64.1 & 94 & $\mathrm{P}<0.001^{* * *}$ \\
\hline $\begin{array}{l}\text { clearly explain the methods of assessment from the start of the } \\
\text { course }\end{array}$ & 46.1 & 84 & $\mathrm{P}<0.001^{* * *}$ \\
\hline Faculty members provide positive feedback after each assessment & 34.2 & 70 & $\mathrm{P}<0.001^{* * *}$ \\
\hline encourage students for self-directed learning & 50.8 & 77 & $\mathrm{P}<0.001^{* * *}$ \\
\hline encourage students for electronic learning & 50.8 & 77 & $\mathrm{P}<0.001^{* * *}$ \\
\hline usually available in their office hours & 23.2 & 50 & $P<0.001^{* * *}$ \\
\hline Overall satisfaction & 46.5 & 75.6 & $\mathrm{P}<0.001^{* * *}$ \\
\hline
\end{tabular}


implement integration in other modules in which they were involved.

The result of the course evaluation questionnaire completed by students showed that overall student satisfaction was $53.88 \%$ in 2009/2010 and 72.65 in 2010/ 2011. There was a highly significant increase in student satisfaction regarding CVS module contents in 2010/ 2011 compared to the previous year, see Table 3. When it came to satisfaction with the module teaching faculty members, there was a significant increase in overall student satisfaction in 2010/2011, see Table 3. It was noted that there was a significant increase in the overall student satisfaction with the CVS assessment plan in 2010/2011, see Table 4. On the other hand, there was an insignificant increase in overall student satisfaction with the educational resources provided in the CVS in 2010/2011when compared to the previous year, see Table 4.

Though the overall success rate was higher (100\%) during the academic year of 2009/2010 when compared to that of $2010 / 2011$ (98.6\%), the percentage of students who received an A grade was significantly higher in (2010/2011). On the other hand, the percentage of students who got a D grade was significantly lower in (2010/2011) see Table 5.

Item analysis of the CVS exams for the two consecutive years (2009/2010 and 2010/2011) was carried out. Regarding the difficulty index, the results showed that the majority of the exam items given in 2009/2010 were very easy (36.6 \%) and easy (50 \%) items. After implementation of the developed integrated module, the percentages of the very easy and easy items had been reduced to $11.7 \%$ and $48.3 \%$ respectively. The percentage of the excellent items increased from 14.4 in 2009/ 2010 to 36.7 in 2010/2011, see Table 6.

Regarding the discrimination index, the results showed that the percentage of the very good discriminating items increased from $13.3 \%$ in $2009 / 2010$ to $70 \%$ in $2010 / 2011$. On the other hand, the percentage of the poor discriminating items, the items that need to be rejected, decreased from $16.6 \%$ in $2009 / 2010$ to $1.7 \%$ in 2010/2011, see Table 6.

Because of the small number of faculty members involved in the CVS module teaching, significance tests could not be applied to the module evaluation questionnaire completed by them. Instead, the percent of change

Table 4 Results of students response to the course evaluation questionnaire (in relation to assessment and educational resources) of the CVS module in (2009/2010) and (2010/2011)

\begin{tabular}{|c|c|c|c|}
\hline Items of comparison & $\begin{array}{c}2009 / 2010 \\
\text { Satisfaction } \\
\mathrm{N}=129 \\
\%\end{array}$ & $\begin{array}{c}2010 / 2011 \\
\text { Satisfaction } \\
\mathrm{N}=152 \\
\%\end{array}$ & $\begin{array}{c}\text { Test of } \\
\text { significance }\end{array}$ \\
\hline \multicolumn{4}{|c|}{ Assessment } \\
\hline Assessment methods were fair & 41.7 & 75 & $P<0.001^{* * *}$ \\
\hline Assessment reflects what was taught. & 43.6 & 84 & $P<0.001^{* * *}$ \\
\hline Assessment method challenge students more than memorize. & 50 & 85 & $P<0.001^{* * *}$ \\
\hline Number of tests was reasonable for the course. & 55.4 & 76 & $P=0.001^{* *}$ \\
\hline These is Formative assessment & 37.9 & 75 & $P<0.001^{* * *}$ \\
\hline The time of formative assessment is suitable. & 37.9 & 75 & $P<0.001^{* * *}$ \\
\hline Overall satisfaction & 44.5 & 65.8 & $P<0.001^{* * *}$ \\
\hline \multicolumn{4}{|c|}{ Educational resources } \\
\hline Educational materials were available. & 66.7 & 67 & $P=0.96$ \\
\hline $\begin{array}{l}\text { Educational materials posted of EMES MED } \\
\text { (education management of electronic system for Medicine) } \\
\text { at earlier time. }\end{array}$ & 39.3 & 50 & $P=0.084$ \\
\hline I frequently use the library to search learning material. & 39.3 & 69 & $P<0.001^{* * *}$ \\
\hline $\begin{array}{l}\text { The library contains adequate number of books for the } \\
\text { course. }\end{array}$ & 45.3 & 72 & $P<0.001^{* * *}$ \\
\hline Lecture rooms are well-equipped. & 45.3 & 62 & $P=0.006^{* *}$ \\
\hline Laboratories are well-equipped & 53.2 & 64 & $P=0.084$ \\
\hline Rooms for PBL are well constructed & 53.2 & 51 & $P=0.81$ \\
\hline $\begin{array}{l}\text { Student's study guide helped me much throughout the } \\
\text { course. }\end{array}$ & 35.5 & 59 & $\mathrm{P}<0.001^{* * *}$ \\
\hline Overall satisfaction & 54 & 61.7 & $P=0.23$ \\
\hline
\end{tabular}


Table 5 Final scores of the students in final CVS module exam in (2009/2010) and (2010/2011)

\begin{tabular}{|c|c|c|c|}
\hline Grade & $\begin{array}{c}2009 / 2010 \\
N=344 \\
N \%\end{array}$ & $\begin{array}{c}2010 / 2011 \\
N=379 \\
N \%\end{array}$ & $\begin{array}{c}\text { Test of } \\
\text { significance }\end{array}$ \\
\hline $\mathrm{A}$ & $26(7.5)$ & $85(22.4)$ & \multirow{6}{*}{$\begin{array}{l}\text { Chi-square } \\
\text { test }=37.29 \\
P<0.001^{* * *}\end{array}$} \\
\hline $\bar{B}$ & $94(27.3)$ & $123(23.4)$ & \\
\hline$C$ & $94(27.3)$ & $83(21.8)$ & \\
\hline$D$ & $130(37.7)$ & $53(13.9)$ & \\
\hline $\bar{F}$ & $0(0)$ & $5(1.3)$ & \\
\hline $\begin{array}{l}\text { Overall success } \\
\text { rate }\end{array}$ & $344(100)$ & 374 (98.6) & \\
\hline
\end{tabular}

was calculated for each assessed item. The results showed that there was a $51 \%$ increase in the overall faculty member satisfaction with the module in 2010/2011. The percentage of increase in the satisfaction index with all of the assessed items did not exceed $50 \%$, except in five items. These include: encouraging SDL, building student analytical and problem solving skills, implementing PBL successfully, availability of learning resources and alignment between the course objectives, instruction and assessment Table 7.

\section{Discussion}

Medical and dental education curricula are continually developing by incorporating advancements, such as horizontal and vertical integration, to address the contemporary needs of their students [9].

Curriculum integration enables learners to recognize how diverse concepts and/or processes interrelate [10]. This concept has received much attention across the health sciences $[9,11]$. The clear build-up of the curriculum and the vertical and horizontal integration of subject knowledge seem to have significantly reduced the lack of regulation [12]. As a result, the faculty of medicine at KAU was encouraged to launch an integrated, system- based curriculum to be delivered to students during Phase I (pre-clerkship years).

Since the planned and delivered curriculum can be significantly different, the first question which came to the authors' mind was, 'How much does the delivered curriculum differ from the planned integrated curriculum? [13], to answer this question, the ME team investigated both student and faculty member satisfaction with the integrated curriculum through both qualitative and quantitative methods.

On designing the newly developed interdisciplinary, integrated CVS module, the tips described by Malik and Malik were beneficial. They described how integration can be enhanced from harmonization to interdisciplinary integrated level by avoiding commonly committed mistakes [14].
Table 6 Difficulty and Discrimination indexes of the items of the CVS module exam in (2009/2010) and (2010/2011)

\begin{tabular}{ccc}
$2009 / 2010$ & $2010 / 2011$ & Test of \\
$\mathrm{N}=60$ & $\mathrm{~N}=60$ & significance \\
$\mathrm{N} \%$ & $\mathrm{~N} \%$ & \\
\hline
\end{tabular}

\begin{tabular}{|c|c|c|c|}
\hline Difficulty index & & & \\
\hline $\begin{array}{l}\text { Very easy } \\
\text { (Conditionally } \\
\text { acceptance) (0.9-1) }\end{array}$ & $22(36.6)$ & $7(11.7)$ & \multirow{5}{*}{$\begin{array}{l}\text { Chi-square } \\
\text { test with } \\
\text { liner trends } \\
X^{2}=16.31 \\
P=0.009^{* *}\end{array}$} \\
\hline Easy (0.70-0.9) & $30(50)$ & $29(48.3)$ & \\
\hline Excellent (0.3-0.7) & $8(14.4)$ & $22(36.7)$ & \\
\hline Moderate (0.15-0.30) & - & $2(3.3)$ & \\
\hline Too difficult $(\leq 0.15)$ & - & - & \\
\hline
\end{tabular}

\begin{tabular}{lccc}
\hline Discrimination index & & & \\
\hline $\begin{array}{l}\text { Very good item } \\
(\geq 0.30)\end{array}$ & $8(13.3)$ & $42(70)$ & $\begin{array}{l}\text { Chi-square } \\
\text { test with } \\
\text { liner trends } \\
X^{2}=44.6 \\
P<0.001^{* *}\end{array}$ \\
$\begin{array}{llll}\text { Reasonably good } \\
(0.20-0.29)\end{array}$ & $8(13.3)$ & $9(15)$ & \\
\hline $\begin{array}{l}\text { Marginal } \\
\text { item (0.09-0.20) }\end{array}$ & $11(18.3)$ & $1(1.7)$ & \\
\hline $\begin{array}{l}\text { Poor } \\
\text { (zero) }\end{array}$ & $10(16.6)$ & - & \\
\hline $\begin{array}{l}\text { Unaccepted } \\
\text { discrimination } \\
\text { (Negative) }\end{array}$ & $2(3.3)$ & & \\
\hline
\end{tabular}

The overall satisfaction of the students after implementation of the integrated CVS module in 2010/2011 was $72.65 \%$. It seemed to be slightly lower than the overall student satisfaction rate $(77.63 \%)$ that was recorded by Mehr et al. The latter results were obtained after assessing an elective integrated training module of the brain's basal ganglia which was designed and implemented by a multidisciplinary team [15].

This study revealed a significant increase in overall student satisfaction (from $53.88 \%$ to $72.65 \%$ ) after implementation of the interdisciplinary integrated module. These results seemed to be in agreement with the results obtained by Klement et al. while they reported Morehouse School of Medicine experience in integrating its first year medical curriculum in 2005. The integration process was expanded to include first year basic science courses (Human Morphology, Biochemistry, Physiology, and Neurobiology). The outcomes of the restructured curriculum include higher or equivalent subject examination average scores, enhanced student satisfaction [16].

These results were in contradict with the findings of Harvard medical school in 2011 when it replaced its dedicated Preventive Medicine and Nutrition course with an integrated curriculum and assessed student satisfaction with both of them. It was found that students with the integrated curriculum were less satisfied with both the quantity and quality of their nutrition education [17]. This decreased satisfaction could be attributed to the reduced content of the integrated curriculum that 
Table 7 Results of course evaluation questionnaire by teaching faculty of the CVS module in (2009/2010) and (2010/2011)

\begin{tabular}{|c|c|c|c|}
\hline Items of comparison & $\begin{array}{c}2009 / 2010 \\
\text { Satisfaction } \\
\text { Index }\end{array}$ & $\begin{array}{c}\text { 2010/2011 } \\
\text { Satisfaction } \\
\text { Index }\end{array}$ & $\begin{array}{l}\text { Percentage of } \\
\text { change }\end{array}$ \\
\hline Integration is implemented during instruction & 60 & 88 & 46 \\
\hline Learning objectives were made clear to students from the start & 72 & 88 & 22 \\
\hline Learning objectives were made clear to faculty members from the start & 70 & 80 & 17 \\
\hline Course encourages SDL & 55 & 84 & 52 \\
\hline Course encourage group work & 62 & 80 & 29 \\
\hline Course build students analytical and problem solving skills & 55 & 84 & 52 \\
\hline PBL was successfully implemented as planned & 60 & 92 & 53 \\
\hline Learning resources available helping in implementing the course objectives & 45 & 88 & 95 \\
\hline Course web pages were relevant to course objectives & 42 & 58 & 38 \\
\hline Number of staff members is sufficient in relation to tasks of the course & 60 & 86 & 43 \\
\hline $\begin{array}{l}\text { There is alignment between the course objectives, instruction and } \\
\text { assessment }\end{array}$ & 46 & 84 & 82 \\
\hline Assessment is based on a blueprint. & 40 & 60 & 33 \\
\hline Various methods of assessment are used & 55 & 70 & 30 \\
\hline Formative assessment without scores are used & 60 & 84 & 38 \\
\hline Early feedback is provided to students & 61 & 84 & 37 \\
\hline There is continuous and final summative assessment & 70 & 90 & 28 \\
\hline The course team utilizes the results of interpretation of item analysis & 55 & 82 & 49 \\
\hline Overall statistical index & 53 & 80 & 51 \\
\hline
\end{tabular}

did not satisfy student curiosity. That was not the case in this study as a sufficient amount of content was secured in the integrated CVS module.

It was found that the overall success rate was lower in $2010 / 2011$ than in 2009/2010 (98.6 \% and $100 \%$ respectively). This might indicate that the exams of the integrated module were more difficult and discriminating and signified a more effective assessment plan.

Implementing case-based teaching seemed to be one of the causes that elicited an increase in student satisfaction in this study and was described by previous ones [18]. Although the ME team failed to convince the CVS teaching faculty to reduce the number of lectures, student satisfaction was not compromised but actually increased. The finding was in accordance with other researches [19].

Fostering SDL was among the methods that the ME team stressed during the integration elements as its role was emphasized by previous studies [20,21]. Weekly, online, formative assessment (quizzes) using the electronic system was another method which was introduced to provide regular feedback to students on their learning process. This was advised by Wilkerson et al. and had proven effective [22].

Among the challenges facing the ME team was the inherent resistance of some faculty member to any change. Regular weekly meetings with the CVS module committee were sufficient to convince and motivate them. It was challenging to make SDL standardized as faculty members were conducting it in different ways and some of them did not assess it at all. The team put together standardized regulations for SDL, starting from setting its topics, learning objectives and assessment method and providing feedback on student learning. Increasing the weight of the SDL (percentage of its hours from the total contact hour allotted to the module) was another challenge that faced the team. This was because faculty members had strong beliefs in the effectiveness of the teacher centered approach and did not rely on SDL as an active and effective approach to student learning.

It was challenging to convince the faculty members of different disciplines to share constructing test integrated items that tackle different disciplines on assessment. They believed that the item construction process should be a confidential and individual process that should not be shared with others. The ME team had conducted workshops to train them and succeeded to convince them to do so after demonstrating the educational impact of integrated assessment on student learning.

\section{Conclusion}

Since the prevailing trend in basic science curriculum changes is now towards integration, demonstrating this experience of upgrading the integration level within the pre-clerkship curriculum and documenting its effectiveness could be helpful for medical schools that are willing 
to enhance integration levels in their curriculum. It could also prove useful to those who intend to integrate their conventional discipline-based curriculum in order to help their students to cross-link and tie information to clinical applications and recall it after the transition to clinical clerkships.

\section{Competing interests}

The authors report no declarations of interest.

\section{Acknowledgments}

The authors would like to thank the CVS committee members for their enthusiasm in improving their module and for collaboration with the ME team. Special thanks for professor Mahmod S. Alahwal, Dean of the Faculty of Medicine, King Abdulaziz University and Dr. Abdulaziz Boker, head of the ME department on providing help, guidance and support of the ME team.

\section{Author details}

'Medical Education Department, Faculty of Medicine, King Abdulaziz University, Jeddah, Saudi Arabia. ${ }^{2}$ Faculty of Medicine, Mansoura University, Mansoura, Egypt. ${ }^{3}$ Director of Cardiovascular system module, Professor of Physiology, Faculty of Medicine, King Abdulaziz University, Jeddah, Saudi Arabia. ${ }^{4}$ Professor of Physiology, Faculty of Medicine, Ein-Shams University, Cairo, Egypt.

\section{Authors' contributions}

NNA shared in research conception and design, acquisition of data, interpretation of data in addition to writing the manuscript and revising it critically and final approval of the version to be published. BSE shared in research conception and design, acquisition of data, analysis of data in addition to revising manuscript critically and final approval of the version to be published. LAA shared in research conception and design, writing the manuscript and revising it critically and final approval of the version to be published. AFA shared acquisition of data, revising the manuscript critically and final approval of the version to be published. All authors read and approved the final manuscript.

\section{Authors' information}

NASRA N. AYUOB is assistant professor in the Medical Education Department, faculty of medicine. She is particularly interested in curriculum designing and integration. She is one of the members of the MED who are responsible for providing educational services to the basic science departments. She is a physician. She had a master and MD in the microscopic Anatomy in addition to a joint master in Medical education JMHPE for Maastricht. BASEM S. ELDEEK is associate professor in the Medical Education Department, faculty of medicine. He is particularly interested in medical education research. He is one of the members of the MED who are responsible for providing educational services to the clinical departments. She is a physician. He had a master and MD in the public health in addition to a joint master in Medical education JMHPE for Maastricht.

LANA A. ALSHAWA is assistant professor in the Medical Education Department, faculty of medicine. She is particularly interested in PBL. She is one of the members of the MED who are responsible for providing educational services to the basic science departments. She is a dentist. She had a PhD in PBL.

ABDULRAHMAN F. ALSABA is professor of physiology, faculty of medicine. $\mathrm{He}$ is the head of the CVS module committee.

Received: 15 March 2012 Accepted: 2 July 2012

Published: 2 July 2012

\section{References}

1. Cooke M, Irby DM, Sullivan W, Ludmerer KM: American medical education 100 years after the Flexner report. NEJM 2006, 355:1339-1344.

2. Harden R, Sowden S, Dunn WR: Education strategies in curriculum development: The SPICES model. Med Educ 1984, 18:284-297.

3. Irby DM, Wilkerson L: Educational innovations in academic medicine and environmental trends. J Gen Int Med 2003, 18:370-376.

4. Woods NN: Science is fundamental: The role of biomedical knowledge in clinical reasoning. Med Educ 2007, 41:1173-1117.
5. Prince $\mathrm{KJAH}$, van de Wiel MWJ, Scherpbier AJJA, van der Vleuten CPM, Boshuizen HPA: A qualitative analysis of the transition from theory to practice in undergraduate training in a PBL medical school. Adv Health Sci Educ 2000, 5:105-116.

6. Blake RL, Hosokawa MC, Riley SL: Student performances on Step 1 and Step 2 of the United States Medical Licensing Examination following implementation of a problem-based learning curriculum. Acad Med 2000, 75(1):66-70.

7. Hoffman K, Hosokawa M, Blake R Jr, Headrick L, Johnson G: Problem-based learning outcomes: ten years of experience at the University of Missouri-Columbia School of Medicine. Acad Med 2006, 81(7):617-625.

8. Moore GT, Block SD, Style CB, Mitchell R: The influence of the new pathway curriculum on Harvard medical students. Acad Med 1994 69:983-989.

9. Kingsley K, O'Malley S, Stewart T, Howard KM: Research enrichment evaluation of structured research in the curriculum for dental medicine students as part of the vertical and horizontal integration of biomedical training and discovery. BMC Med Educ 2008, 8:9.

10. Kalkwarf KL, Haden NK, Valachovic RW: ADEA Commission on Change and Innovation in Dental Education. J Dent Educ 2005, 69(10):1085-1087.

11. Jansen DA, Morse WA: Positively influencing student nurse attitudes toward caring for elders: results of a curriculum assesment study. Gerontol Geriatrics Educ 2004, 25(2):1-14.

12. Van Der Veken J, Valcke M, De Maeseneer J, Derese A: Impact of the transition from a conventional to an integrated contextual medical curriculum on students' learning patterns: A longitudinal study. Med teach 2009, 31:433-441.

13. Prideaux $D: A B C$ of learning and teaching in medicine Curriculum design. BMJ 2003, 326:268-270.

14. Malik AS, Malik RH: Twelve tips for developing an integrated curriculum. Med Teach 2011, 33(2):99-104.

15. Mehr SE, Hassanzadeh G, Zahmatkesh M, Seyedian M, Arbabi M, Mirzazadeh A, Hatami F: Medical Students' Viewpoint Regarding the Integrated Module of Basal Ganglia. Acta Medica Iranica 2011, 49(11):753-759.

16. Klement BJ, Paulsen DF, Wineski LE: Anatomy as the backbone of an integrated first year medical curriculum: Design and implementation. Anat Sci Educ 2011, 4:157-169.

17. Walsh CO, Ziniel SI, Delichatsios HK, Ludwig DS: Nutrition attitudes and knowledge in medical students after completion of an integrated nutrition curriculum compared to a dedicated nutrition curriculum: a quasi-experimental study. BMC Med Educ 2011, 11:58. http://www.biomedcentral.com/1472-6920/11/58.

18. Drake SM, Burns RC: Meeting standards through integrated curriculum. VA: Association for Supervision and Curriculum Development, Alexandria; 2004.

19. Ho MT, Tani M: What medical students value from their teachers. Aust Health Rev 2007, 31:358-6.

20. Shaughnessy AF, Slawson DC: Are we providing doctors with the training and tools for lifelong learning? Interview by Abi Berger. BMJ 1999, 319:1280.

21. Spencer J, Jordan R: Educational outcomes and leadership to meet the needs of modern health care. Qual Health Care 2001, 10(Suppl 2):ii38-ii45.

22. Wilkerson L, Stevens Cm, Krasne S: No content without context: Integrating basic, clinical, and social sciences in a pre-clerkship curriculum. Med teach 2009, 31:812-821.

doi:10.1186/1472-6920-12-50

Cite this article as: Ayuob et al:: Interdisciplinary Integration of the CVS

Module and Its Effect on Faculty and Student Satisfaction as Well as Student Performance. BMC Medical Education 2012 12:50. 